\title{
Changes in cardiac arrest patients' temperature management after the 2013 "TTM" trial: results from an international survey
}

Nicolas Deye ${ }^{1 *}$, François Vincent ${ }^{2}$, Philippe Michel ${ }^{3}$, Stephan Ehrmann ${ }^{4}$, Daniel da Silva ${ }^{5}$, Michael Piagnerelli ${ }^{6}$, Antoine Kimmoun ${ }^{7}$, Olfa Hamzaoui ${ }^{8}$, Jean-Claude Lacherade ${ }^{9}$, Bernard de Jonghe ${ }^{10}$, Florence Brouard ${ }^{3}$, Corinne Audoin ${ }^{11}$, Xavier Monnet ${ }^{12}$, Pierre-François Laterre ${ }^{13}$ and For the SRLF Trial Group

\begin{abstract}
Background: Therapeutic hypothermia ( $\mathrm{TH}$ between 32 and $34^{\circ} \mathrm{C}$ ) was recommended until recently in unconscious successfully resuscitated cardiac arrest (CA) patients, especially after initial shockable rhythm. A randomized controlled trial published in 2013 observed similar outcome between a $36^{\circ} \mathrm{C}$-targeted temperature management (TTM) and a $33^{\circ} \mathrm{C}$-TTM. The main aim of our study was to assess the impact of this publication on physicians regarding their TTM practical changes.
\end{abstract}

Methods: A declarative survey was performed using the webmail database of the French Intensive Care Society including 3229 physicians (from May 2014 to January 2015).

Results: Five hundred and eighteen respondents from 264 ICUs in 11 countries fulfilled the survey (16\%). A specific attention was generally paid by $94 \%$ of respondents to TTM (hyperthermia avoidance, normothermia, or TH implementation) in CA patients, whereas $6 \%$ did not. TH between 32 and $34^{\circ} \mathrm{C}$ was declared as generally maintained during $12-24 \mathrm{~h}$ by $78 \%$ of respondents or during $24-48 \mathrm{~h}$ by $19 \%$. Since the TTM trial publication, $56 \%$ of respondents declared no modification of their TTM practice, whereas $37 \%$ declared a practical target temperature change. The new temperature targets were $35-36{ }^{\circ} \mathrm{C}$ for $23 \%$ of respondents, and $36^{\circ} \mathrm{C}$ for $14 \%$. The duration of overall TTM (including TH and/or normothermia) was declared as applied between 12 and $24 \mathrm{~h}$ in $40 \%$, and between 24 and $48 \mathrm{~h}$ in $36 \%$. In univariate analysis, the physicians'TTM modification seemed related to hospital category (university versus non-university hospitals, $P=0.045)$, to TTM-specific attention paid in CA patients $(P=0.008)$, to TH durations $(<12$ versus $24-48 \mathrm{~h}, P=0.01$ ), and to new targets temperature (32-34 versus $\left.35-36{ }^{\circ} \mathrm{C}, P<0.0001\right)$.

Conclusions: The TTM trial publication has induced a modification of current practices in one-third of respondents, whereas the $32-34^{\circ} \mathrm{C}$ target temperature remained unchanged for $56 \%$. Educational actions are needed to promote knowledge translations of trial results into clinical practice. New international guidelines may contribute to this effort.

Keywords: Survey, Therapeutic hypothermia, Targeted temperature management, Cooling, Temperature, Heart arrest

\section{Background}

Targeted temperature management (TTM) has been shown to improve outcome in adult patients successfully

\footnotetext{
*Correspondence: nicolas.deye@lrb.aphp.fr

${ }^{1}$ Réanimation Médicale et Toxicologique, Unité Inserm U942, Centre Hospitalier Universitaire Lariboisière, Assistance Publique des Hôpitaux de Paris, 2, rue Ambroise Paré, 75010 Paris, France

Full list of author information is available at the end of the article
}

resuscitated from cardiac arrest (CA) [1-4]. However, several issues such as the optimal level of TTM or the optimal method of cooling still remained unsolved [4, 5]. The recent publication of the large TTM trial by Nielsen and co-workers seemed to answer, at least partially, those questions [6]. No main outcome differences were observed between the two evaluated levels of TTM: $33{ }^{\circ} \mathrm{C}$ (corresponding previously to therapeutic 
hypothermia: $\mathrm{TH}$ ) versus $36{ }^{\circ} \mathrm{C}$ both applied during $28 \mathrm{~h}$. However, this trial mostly included out-of-hospital CA patients with relatively short no-flow durations occurring from both initial non-shockable and shockable rhythms. Conversely, the European trial had previously compared a $33{ }^{\circ} \mathrm{C}-\mathrm{TTM}$ group versus a control group without a specific temperature management protocol in patients after CA from shockable rhythm only and more prolonged no-flow durations [7]. Finally, the three main randomized trials evaluating TTM after CA seem to highlight that all TTM procedures (e.g., $36{ }^{\circ} \mathrm{C}-\mathrm{TTM}$ and $33{ }^{\circ} \mathrm{C}$-TTM) are similarly beneficial when compared with non-TTM regimen [1, 2, 6-8]. This issue, also reinforced by a recent meta-analysis, has been recalled by the International Liaison Committee On Resuscitation (ILCOR) experts, possibly to avoid any definitive abandon of TTM implementation after CA $[9,10]$. Indeed these experts assume that the published studies do not support a treatment strategy where TTM is abandoned but support a strategy where either 33 or $36{ }^{\circ} \mathrm{C}$-TTM remains an important component of post-CA treatment [9]. However, to the best of our knowledge, no study has to date evaluated the potential impact of these different TTM trials on the post-CA management.

Following the main studies on TH published in 2002 [1, 2], the initial surveys showed relatively low rates of TH implementation overall ranging from 13 to $28 \%$ with variations according to countries [11-15]. After the first TH guidelines published in 2003 [16], widespread TH implementation seemed to occur progressively. Indeed, two consecutive surveys performed in Poland found that the number of intensive care units (ICUs) using TH increased threefold in the 5-year period of 2005-2010 [17, 18]. Similarly, two consecutive surveys found a major increase in $\mathrm{TH}$ use from 28.4 to $85.6 \%$ between 2006 and 2010 in the United Kingdom $[15,19]$. Finally, a declarative survey performed in France reported up to $98 \%$ adherence to recommendations regarding $\mathrm{TH}[20]$. As the pendulum may swing back to an adaptive "lighter" TTM or a non-TTM approach in resuscitated CA patients, we decided to conduct a survey to assess the potential impact of the recent studies published on the practical management of such patients.

\section{Methods}

A declarative survey was performed among 3229 physician members of the French Intensive Care Society (FICS/SRLF), including numerous French-speaking countries. The first email was sent on May 23, 2014, followed by eight new mailings sent monthly until January 8, 2015 (several answers per ICU were allowed). Respondents received no compensation for their participation in the survey.
A questionnaire written in French was developed by a senior intensivist experienced in CA and TTM, and implemented using SurveyMonkey ${ }^{\circledR}$. The study group tested the questionnaire and worked on rephrasing and improvement. The survey was made of 74 questions, of which 19 needed mandatory answers and included those focusing on TTM practice in CA patients (see Additional file 1). Briefly, the questionnaire was divided into four parts: (1) Characteristics of the ICU and the respondent; (2) General and cardiovascular management of CA; (3) TTM in CA patients (indication for TH use, changes induced by the Nielsen trial [6], cooling methods); and (4) Prognostication in CA patients. Except for quantitative questions, responses were obtained either using a bimodal answer ("yes/no") or a 4-point Likert scale (structured as "always/frequently/sometimes/never").

\section{Statistics}

Quantitative variables were expressed as mean (standard deviation) when following a Gaussian distribution or median (interquartile range 25-75\%) otherwise, and were compared using the Student $t$ or Mann-Whitney test, respectively. Qualitative variables were expressed as frequencies ( $95 \%$ confidence interval) calculated by angular transformation, and were compared using the Chi Square or Fisher exact probability test for categorical variables. Data were tested for normality using the Shapiro Normality Test. Multivariate analyses were performed using logistic regression. All tests were two-sided with $5 \%$ significance, and performed using the R software ( $R$ package version 2.14.1.6, Vienna, Austria).

\section{Results}

Five hundred and eighteen respondents fulfilled the survey $(16 \%)$, representing an absolute number of 264 ICUs (France: 219; Belgium: 18; Africa: 16; others from Europe: 9; Canada: 2). General characteristics of respondents and their ICUs are described in Table 1 . The distribution of responses over time is depicted in Additional file 2: Figure S1.

\section{Targeted temperature management (TTM)}

Specific attention is generally paid to temperature management (normothermia, avoiding hyperthermia, or TTM implementation) in successfully resuscitated and unconscious CA patients as declared by $94 \%$ of respondents, mainly using $\mathrm{TH}$ in $89 \%$. The reasons why TH is not applied are depicted in Additional file 2: Figure S2. Indications of TH implementation in successfully resuscitated and unconscious CA patients are described in Table 2. Temperature monitoring after CA is mainly performed using a bladder probe as reported by $42 \%$ 
Table 1 Characteristics of respondents (number of respondents: $\boldsymbol{N}$ ) and their intensive care unit

\begin{tabular}{|c|c|}
\hline \multicolumn{2}{|l|}{ Type of hospital $(N=509)$} \\
\hline Public university hospital & $249(49)$ \\
\hline Public non-university hospital & $228(45)$ \\
\hline Private hospital & $27(5)$ \\
\hline Other & $5(1)$ \\
\hline \multicolumn{2}{|l|}{ Country $(N=515)$} \\
\hline France & $448(87)$ \\
\hline Other in Europe & $38(7)$ \\
\hline Africa & $25(5)$ \\
\hline Canada & $4(1)$ \\
\hline \multicolumn{2}{|l|}{ ICU staff $(N=500)$} \\
\hline Attending full-time physicians, mean \pm SD & $7.2 \pm 3.8$ \\
\hline Resident and fellow, mean \pm SD & $4.8 \pm 4.2$ \\
\hline ICU beds, mean \pm SD $(N=448)$ & $15 \pm 7$ \\
\hline \multicolumn{2}{|c|}{ ICU activity during the last full year (2013) prior to the present study } \\
\hline \multicolumn{2}{|l|}{ Overall admissions $(N=500)$} \\
\hline$<300$ & $22(4)$ \\
\hline $300-500$ & $125(25)$ \\
\hline $500-800$ & $145(29)$ \\
\hline$>800$ & $208(42)$ \\
\hline \multicolumn{2}{|l|}{ Admissions for $C A(N=518)$} \\
\hline$<10$ & $70(14)$ \\
\hline $10-20$ & $154(30)$ \\
\hline $20-30$ & $76(15)$ \\
\hline $30-40$ & $60(12)$ \\
\hline $40-50$ & $45(9)$ \\
\hline$>50$ & $113(22)$ \\
\hline \multicolumn{2}{|l|}{ TH implementation $(N=384)$} \\
\hline$<10$ & $74(19)$ \\
\hline $10-20$ & $120(31)$ \\
\hline $20-30$ & $54(14)$ \\
\hline $30-40$ & $45(12)$ \\
\hline $40-50$ & $34(9)$ \\
\hline$>50$ & $57(15)$ \\
\hline Use of a written CA procedure $(N=509)$ & $221(43)$ \\
\hline No available CA procedure in the ICU & $259(52)$ \\
\hline $\begin{array}{l}\text { In-hospital cath lab performing coronary } \\
\text { angiography }(N=518)\end{array}$ & $363(70)$ \\
\hline With a $24 \mathrm{~h} / 24 \mathrm{~h}$ availability & $353(97)$ \\
\hline
\end{tabular}

Results are expressed as $n(\%)$ unless specified otherwise

of respondents, and/or an esophageal probe by $41 \%$ of respondents (Additional file 2: Figure S3).

$\mathrm{TH}$ was declared as never induced using intravenous cold fluids by $38 \%$ of respondents (Table 3 ). TH was reported to be always induced and/or maintained using basic external methods (fan and ice packs) by $34 \%$, whereas other methods of cooling were more rarely used. TH between 32 and $34^{\circ} \mathrm{C}$ was declared as generally
Table 2 Indications for therapeutic hypothermia implementation after successfully resuscitated and unconscious cardiac arrest patient ( $N$ respondents)

\begin{tabular}{lc}
\hline Out-of-hospital CA from initial shockable rhythm ${ }^{\mathrm{a}}(\mathrm{N}=403)$ & \\
Always & $258(64)$ \\
Frequently & $75(19)$ \\
Sometimes & $24(6)$ \\
Never & $29(7)$ \\
Do not know & $17(4)$ \\
Out-of-hospital CA from initial non-shockable rhythm ${ }^{\mathrm{b}}(\mathrm{N}=403)$ & \\
Always & $134(33)$ \\
Frequently & $129(32)$ \\
Sometimes & $73(18)$ \\
Never & $51(13)$ \\
Do not know & $16(4)$ \\
In-hospital CA from initial shockable rhythm ${ }^{\mathrm{a}}(\mathrm{N}=399)$ & \\
Always & $229(57)$ \\
Frequently & $85(21)$ \\
Sometimes & $38(10)$ \\
Never & $32(8)$ \\
Do not know & $15(4)$ \\
In-hospital CA from initial non-shockable rhythm ${ }^{\mathrm{b}}(\mathrm{N}=398)$ & \\
Always & $117(29)$ \\
Frequently & $122(31)$ \\
Sometimes & $86(22)$ \\
Never & $60(15)$ \\
Do not know & $13(3)$ \\
\hline Results are express as $n$
\end{tabular}

Results are expressed as $n$ (\%)

$C A$ cardiac arrest

a Ventricular fibrillation/pulseless ventricular tachycardia

${ }^{\text {b } A s y s t o l e / p u l s e l e s s ~ e l e c t r i c a l ~ a c t i v i t y ~}$

maintained during $12-24$ h by $78 \%$ of respondents, or during $24-48$ h by $19 \%$. Passive rewarming was predominantly used by $66 \%$ of respondents. The usual reported rate for active rewarming was $0.5{ }^{\circ} \mathrm{C} / \mathrm{h}$ in $53 \%$ and $0.3^{\circ} \mathrm{C} / \mathrm{h}$ in $25 \%$ of the cases.

Since the TTM trial publication [6], $56 \%$ of respondents declared no modification of their TTM practice, whereas $37 \%$ declared a practical target temperature's change (Additional file 2: Figure S4). This modification is applied in all CA patients in $52 \%$ or in specific CA patients in $34 \%$, mainly in CA from cardiac origin (see details in Additional file 2: Figure S5). The new temperature targets presently preferred by respondents after the Nielsen's trial are depicted in Fig. 1 [6]. The overall duration of the TTM after CA (i.e., including hypothermia whatever its level and/or normothermia) is now mainly applied between 12 and $24 \mathrm{~h}$ by $40 \%$ of respondents, and between 24 and 48 h by $36 \%$ (Fig. 2). Univariate analysis describing factors associated with modifications of the 
Table 3 Methods of cooling used for therapeutic hypothermia implementation after cardiac arrest ( $N$ respondents)

\begin{tabular}{|c|c|}
\hline \multicolumn{2}{|c|}{ Cold intravenous fluid infusion to induce $\mathrm{TH}(\mathrm{N}=396)$} \\
\hline Always & $48(12.1)$ \\
\hline Frequently & $95(24.0)$ \\
\hline Sometimes & $100(25.2)$ \\
\hline Never & $152(38.4)$ \\
\hline Do not know & $1(0.3)$ \\
\hline \multicolumn{2}{|c|}{$\begin{array}{l}\text { Basic surface cooling (fans, ice packs) to induce and/or maintain TH } \\
\qquad(N=395)\end{array}$} \\
\hline Always & $136(34.4)$ \\
\hline Frequently & $91(23.0)$ \\
\hline Sometimes & $93(23.6)$ \\
\hline Never & $74(18.7)$ \\
\hline Do not know & $1(0.3)$ \\
\hline \multicolumn{2}{|c|}{ External water blanket cooling to induce and/or maintain TH $(N=394)$} \\
\hline Always & $57(14.5)$ \\
\hline Frequently & $34(8.6)$ \\
\hline Sometimes & $26(6.6)$ \\
\hline Never & $274(69.5)$ \\
\hline Do not know & $3(0.8)$ \\
\hline \multicolumn{2}{|c|}{ External air blanket cooling to induce and/or maintain TH $(N=396)$} \\
\hline Always & $28(7.1)$ \\
\hline Frequently & $38(9.6)$ \\
\hline Sometimes & $59(14.9)$ \\
\hline Never & $269(67.9)$ \\
\hline Do not know & $2(0.5)$ \\
\hline \multicolumn{2}{|c|}{$\begin{array}{l}\text { External advanced surface cooling gel pads to induce and/or maintain } \\
\text { TH }(N=399)\end{array}$} \\
\hline Always & $10(2.5)$ \\
\hline Frequently & $30(7.5)$ \\
\hline Sometimes & $25(6.3)$ \\
\hline Never & $328(82.2)$ \\
\hline Do not know & $6(1.5)$ \\
\hline \multicolumn{2}{|c|}{ Intravascular device to induce and/or maintain TH $(N=395)$} \\
\hline Always & $28(7.0)$ \\
\hline Frequently & $37(9.2)$ \\
\hline Sometimes & $37(9.2)$ \\
\hline Never & $298(74.3)$ \\
\hline Do not know & $1(0.3)$ \\
\hline
\end{tabular}

temperature level occurring after the TTM trial publication is described in Table 4.

\section{General treatments along TTM}

During the TTM period, patients were reported to always receive sedatives by $85 \%$ of respondents (midazolam $83 \%$ and/or propofol $40 \%$ ), analgesics by $78 \%$ (sufentanil $64 \%$ and fentanyl $23 \%$ ), and neuromuscular blockers by $47 \%$ (cisatracurium $67 \%$ and atracurium $29 \%$ ). A specific protocolized insulin treatment for glycemic control after CA was always used by $59 \%$. Fifty-six percent of respondents reported to never use a specific protocol regarding the $\mathrm{PaO}_{2}$ control, and $43 \%$ to never use a specific protocol regarding the $\mathrm{PaCO}_{2}$ control. Additional results regarding the use of coronary angiography after the return of spontaneous circulation (ROSC), regarding the targeted arterial blood pressure after ROSC, regarding the initial cardiopulmonary resuscitation, regarding the use of brain computerized-tomography scanner, use of ventricular assist devices in refractory CA and in case of severe post-CA shock, and regarding prognostication after $\mathrm{CA}$ are described in the online supplementary files (Additional file 2: Figures S6, S7, S8, and S9; Tables S1, S2).

\section{Discussion}

In this declarative survey, specific attention was generally paid by $94 \%$ of respondents to TTM in unconscious and successfully resuscitated CA patients. The optimal target temperature to reach after $\mathrm{CA}$ remains unchanged for $56 \%$ of respondents, whereas $37 \%$ declare to target a new temperature following the TTM trial publication [6]. The current targets temperature are $32-34{ }^{\circ} \mathrm{C}$ (or $33{ }^{\circ} \mathrm{C}$ ) in $60 \%, 35-36{ }^{\circ} \mathrm{C}$ in $23 \%, 36{ }^{\circ} \mathrm{C}$ in $14 \%$. TTM modifications were more frequently declared by physicians working in university hospitals. At present, TH is never induced using intravenous cold fluids by $38 \%$ of respondents.

\section{TTM modifications}

International guidelines recommended until recently the use of $32-34{ }^{\circ} \mathrm{C}$-targeted $\mathrm{TH}$ in successfully resuscitated unconscious out-of-hospital adult CA patients, mainly for initial shockable rhythm [3]. However, the optimal level of the target temperature remains unknown. In the publication by Nielsen and co-workers, no main differences were observed between the two levels of target temperature: $33^{\circ} \mathrm{C}$ (corresponding previously to $\mathrm{TH}$ ) and $36{ }^{\circ} \mathrm{C}[6]$. Considering debates after this large trial $[7,8$, 21], ILCOR experts published a new recommendation regarding the TTM use after CA [9]. Indeed, since the results of the TTM publication, a significant proportion of physicians may shift back in their practice and abandon all sort of TTM after CA, and resume practice as mainly reported before the 2002 pivotal trials. Our survey confirms that roughly one-third of physicians decided to modify their current practice, mainly by using a smooth depth of TTM. However, most physicians seemed not to abandon the use of temperature management after CA, applying predominantly the previous recommended $33{ }^{\circ} \mathrm{C}$ target or a new $36{ }^{\circ} \mathrm{C}$-TTM. Only a minority of 


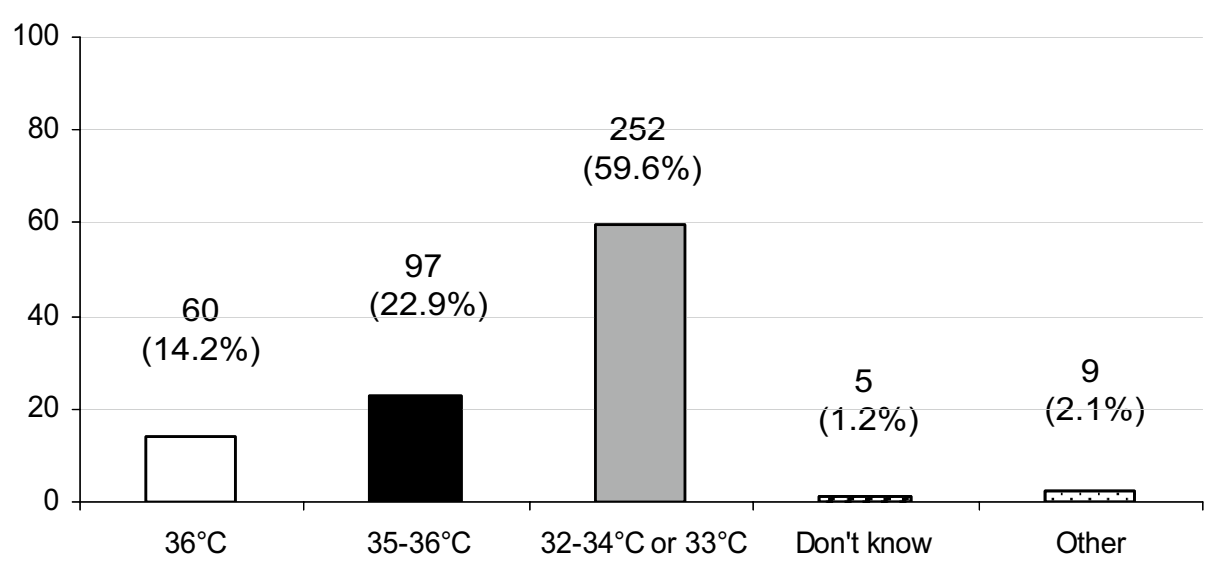

Fig. 1 Distribution of the new targets temperature expressed as absolute number (percentage) after the Nielsen's publication [6] ( $n=423$ respondents, expressed as percentage). Other targets $(n=9,2.1 \%)$ were documented as follows: $37^{\circ} \mathrm{C}(n=4,0.9 \%), 34^{\circ} \mathrm{C}(n=3,0.7 \%)$, and $35^{\circ} \mathrm{C}(n=2$, $0.5 \%)$

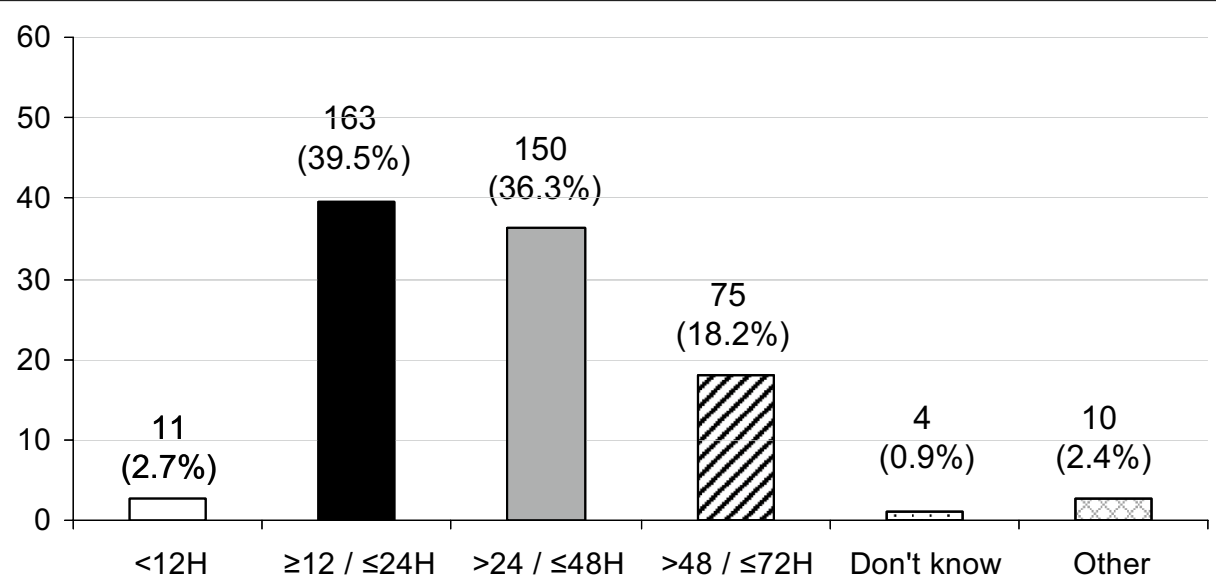

Fig. 2 Distribution of the durations of the overall targeted temperature management period ( $n=413$ respondents, expressed as percentage). Other durations of the overall targeted temperature management phase were documented as follows: $=72 \mathrm{~h}(2),>72 \mathrm{~h}$ (4) miscellaneous (4)

physicians (6\%) herein declared to be unaware of any TTM after CA. This is concordant with a previous survey performed in France, observing a global $98 \%$ adherence to recommendations regarding TTM [20]. Two-third of respondents declared in our survey not to have changed the target temperature, despite the TTM trial [6]. Among respondents who changed their target temperature, the majority decided to choose a TTM set around $36{ }^{\circ} \mathrm{C}$, whereas some respondents decided to target the previous $32-34{ }^{\circ} \mathrm{C}$ range. One may hypothesize that the majority of respondents were not yet deeply convinced by the TTM trial or remained unaware of its publication, whereas some physicians possibly did not have previous protocol in their unit regarding the target temperature, or used a protocol targeting a temperature different from the recommended $32-34{ }^{\circ} \mathrm{C}$ range. Finally, our results seem in accordance with other studies describing that new scientific evidences resulting from recent randomized clinical trials are sometimes poorly implemented in clinical practice, as it has been shown for instance in the tight glycemic control area [22].

Interestingly, most of the respondents who changed their target temperature finally decided to choose preferentially an intermediate range between 35 and $36{ }^{\circ} \mathrm{C}$, instead of the $36^{\circ} \mathrm{C}$ precisely reported in the TTM trial. However, the 2015 ILCOR guidelines, recently published [23], recommend at present "TTM for adults with outof-hospital CA with an initial shockable rhythm at a constant temperature between 32 and $36{ }^{\circ} \mathrm{C}$ for at least $24 \mathrm{~h}$. Similar suggestions are made for out-of-hospital cardiac 
Table 4 Comparison of respondents declaring a target temperature's changes versus those without target temperature's changes after the TTM study publication (univariate analysis)

\begin{tabular}{|c|c|c|c|}
\hline & $\begin{array}{l}\text { Respondents who } \\
\text { changed their TT }\end{array}$ & $\begin{array}{l}\text { Respondents who did not } \\
\text { changed their TT }\end{array}$ & $P$ value \\
\hline University hospital & $90 / 171(52.6)$ & $97 / 224(43.3)$ & 0.045 \\
\hline Public non-university hospital & $65 / 171(38.0)$ & $115 / 224(51.4)$ & \\
\hline Private hospital & 15/171 (8.8) & $9 / 224(4.0)$ & \\
\hline Others & $1 / 171(0.6)$ & $3 / 224(1.3)$ & \\
\hline Number of ICU beds & $15.9 \pm 7.9$ & $15.1 \pm 6.6$ & 0.32 \\
\hline Number of residents and fellows & $5.4 \pm 5.9$ & $4.5 \pm 2.8$ & 0.099 \\
\hline Number of full-time physicians & $7.6 \pm 4.7$ & $6.9 \pm 2.9$ & 0.12 \\
\hline Use of a written CA protocol & $77 / 170(45.3)$ & $102 / 224(45.5)$ & 0.87 \\
\hline Number of admissions <500/year & $45 / 168(26.8)$ & $65 / 223(29.1)$ & 0.21 \\
\hline Number of admissions $>$ 500/year & $123 / 168(73.2)$ & 158/223 (70.9) & \\
\hline Number of CA admissions <30/year & $98 / 172(57.0)$ & $126 / 227(55.5)$ & 0.87 \\
\hline Number of CA admissions >30/year & $74 / 172(43.0)$ & $101 / 227(44.5)$ & \\
\hline Number of TH <30/year & 108/154 (70.1) & $129 / 212(60.8)$ & 0.22 \\
\hline Number of TH >30/year & $46 / 154(29.9)$ & $83 / 212(39.2)$ & \\
\hline In-hospital cath-lab & $124 / 172(72.1)$ & $161 / 227(70.9)$ & 0.87 \\
\hline ECLS use for refractory CA & $92 / 172(53.5)$ & $101 / 227(44.5)$ & 0.07 \\
\hline Optimal ABP targeted & $156 / 171(91.2)$ & $190 / 219(86.8)$ & 0.19 \\
\hline Specific TTM after $C A^{a}$ & 166/171 (97.1) & $213 / 227(93.8)$ & 0.008 \\
\hline No specific TTM after $C A^{a}$ & $5 / 171(2.9)$ & $14 / 227(6.1)$ & \\
\hline TH after $C A^{b}$ & $143 / 172(83.1)$ & $212 / 227(93.4)$ & 0.003 \\
\hline No TH after $C A^{b}$ & $27 / 172(15.7)$ & $15 / 227(6.6)$ & \\
\hline \multicolumn{4}{|l|}{ TH duration } \\
\hline$<12 \mathrm{~h}$ & $8 / 159(5.0)$ & $2 / 212(0.9)$ & 0.01 \\
\hline$\geq 12 \mathrm{~h} / \leq 24 \mathrm{~h}$ & $124 / 159(80.0)$ & $166 / 212(78.3)$ & \\
\hline$>24 h / \leq 48 h$ & 24/159 (15.1) & $44 / 212(20.8)$ & \\
\hline$>48 \mathrm{~h}$ & $3 / 159(1.9)$ & $0 / 212(0.0)$ & \\
\hline Active rewarming & $57 / 156(36.5)$ & $98 / 213(46.0)$ & 0.087 \\
\hline \multicolumn{4}{|l|}{ New TT } \\
\hline $32-34{ }^{\circ} \mathrm{C}$ & $45 / 171(26.3)$ & $194 / 225(86.2)$ & $<0.0001$ \\
\hline $35-36^{\circ} \mathrm{C}$ & $78 / 171(45.6)$ & $15 / 225(6.7)$ & \\
\hline $36^{\circ} \mathrm{C}$ & $44 / 171(25.7)$ & $11 / 225(4.9)$ & \\
\hline Other & $4 / 171(2.4)$ & $5 / 225(2.2)$ & \\
\hline \multicolumn{4}{|l|}{ Overall TTM duration } \\
\hline$<12 \mathrm{~h}$ & $7 / 169(4.1)$ & $3 / 220(1.4)$ & 0.074 \\
\hline$\geq 12 \mathrm{~h} / \leq 24 \mathrm{~h}$ & $75 / 169(44.4)$ & $81 / 220(36.8)$ & \\
\hline$>24 h / \leq 48 h$ & $61 / 169(36.1)$ & $83 / 220(37.7)$ & \\
\hline$>48 \mathrm{~h} / \leq 72 \mathrm{~h}$ & $24 / 169(14.2)$ & $42 / 220(19.1)$ & \\
\hline Other & $2 / 169(1.2)$ & $11 / 220(6.0)$ & \\
\hline
\end{tabular}

Results are expressed as $n$ (\%) unless expressed otherwise

TTM targeted temperature management, $T T$ targeted temperature, $C A$ cardiac arrest, $E C L S$ extracorporeal life support, $A B P$ arterial blood pressure, $T H$ therapeutic hypothermia

a This item corresponds to the following question "In practice, do you generally pay a specific attention to temperature management in successfully resuscitated and unconscious CA patients"

b This item corresponds to the following question "In practice, do you generally use TH in successfully resuscitated and unconscious CA patients"

arrest with a non-shockable rhythm and in-hospital cardiac arrest." In our survey, physicians changing their target temperature mostly applied these modifications for all CA patients, despite that the TTM trial was focused on out-of-hospital CA from cardiac origin. This suggests that physicians could use an adaptive TTM, since 
the TTM trial publication [6], mainly regarding the target temperature and the selection of patients that will receive TTM. However, these choices remain in accordance with these new ILCOR guidelines [23].

As expected in our study, the target temperature's change was related to the TH/TTM characteristics performed by physicians (choice by physicians to perform TH/TTM in unconscious CA patients), and to the new target temperature. However, practical target temperature's change seemed also related to the hospital category (i.e., university hospital or not). Interestingly, the TH/ TTM durations seemed also associated to this temperature change: longer TTM durations seemed more often declared by physicians that did not change their practice. This could be paradoxical with the fact that the TTM trial preferentially used a prolonged duration of TTM as compared with the 2002 pivotal trials $[1,2,6]$. It can be argued that the respondents who changed their practice decided that $\mathrm{TH}$ should be no longer useful and consequently shortened the TH/TTM durations. However, prospective studies are warranted to confirm this issue.

\section{Modifications of the cooling methods}

The majority of respondents herein declared to use basic external methods to implement $\mathrm{TH}$. Close to our results, external methods were used in $54 \%$ of cases in a previous survey conducted in France [20]. Similarly, other surveys observed that surface cooling and/or ice packs were mostly used in ICUs, usually reaching about 50-60\% $[18,19,24,25]$. Our survey confirms that simple and less expensive methods, such as basic and external cooling, may represent the first choice for most physicians, despite that new arguments could modify this issue [26, 27].

Most of respondents declared in our survey that they never induce TH using intravenous cold fluids. In some countries where $\mathrm{TH}$ seemed underused (reaching 21.7, 43 , and $55.1 \%$ of cases), cold fluids as an induction method of cooling are also infrequently used (8.5, 7.4, and $22 \%$ of respondents, respectively) [18, 25, 28]. Conversely, in United Kingdom with an $86 \%$ use of TH, $71 \%$ of respondents stated that TH was usually induced by the rapid infusion of cold fluids [19]. In Germany, cold packs and cold infusions were both equally used in about $60 \%$, mainly because of their lower cost [29]. In the study by Merchant and co-workers, non-United States respondents seemed more likely to cool with cold fluids as compared with United States respondents (36 versus $28 \%$, respectively), while ice packs were used in 40 and $60 \%$, respectively [30]. While $41 \%$ of French ICUs previously declared to use cold fluid for TH induction [31], our survey observed that such cooling was presently not used in $38 \%$ of cases. Indeed, two large randomized controlled studies using cold intravenous fluids to induce $\mathrm{TH}$ in the prehospital setting did not find improvement in outcome as compared with a standard TTM management, leading to important doubts regarding this specific cooling method for TH induction [32, 33]. This is also concordant with the new ILCOR guidelines that recently "recommends against prehospital cooling with rapid infusion of large volumes of cold intravenous fluid" [23]. However, whether "prehospital cooling using a rapid infusion of large volumes of cold intravenous fluid immediately after ROSC is not recommended, it may still be reasonable to infuse cold intravenous fluid where patients are well monitored and a lower target temperature (e.g., $33^{\circ} \mathrm{C}$ ) is the goal" [34].

\section{Other evaluated parameters along TTM}

The previous published survey performed in France observed similar or close results to ours regarding associated treatments used during TTM [20]. However, we observed a slightly higher use of propofol (40\% presently versus $10 \%$ in the previous study) [20]. This could be related to some recent publications showing a possible superiority regarding neurological prognostication by using short half-life sedatives [35]. Additionally, we found a possible lower percentage of use of neuromuscular blocking agents during TTM (47\% presently versus $97 \%$ previously) [20]. To the best of our knowledge, our study is the first to evaluate the extremely low use of a specific protocol regarding $\mathrm{PaO}_{2}$ and $\mathrm{PaCO}_{2}$, despite the probable impact of such interventions $[8,36,37]$. This contrasts with glycemic control protocols that were here reported to be frequently used, suggesting that this parameter seems important for respondents as previously suggested in CA [38]. To the best of our knowledge, our survey is also the first to describe other TTM's associated treatments of the post-CA period, such uses of coronary angiography and ventricular assist devices, and the arterial pressure target after CA along TTM (see the online supplement).

\section{Limitations}

While offering new insights mainly regarding TTM implementation, our study has several limitations. First, the percentage of respondents is only $16 \%$, limiting results generalization. However, despite a median reported response rate reaching $63.3 \%$ [39], lower response rates have also been described in other declarative surveys, between 2.9 and $18.1 \%$ [40-42]. The usual response rates in the field of $\mathrm{TH}$ range from 13 to $98 \%$, with the lower limit roughly observed in our study [12, $15,20,24,43,44]$. Second, as our survey is purely declarative, discrepancies may exist between our results and the real-life practice. We conducted this survey using the 
FICS website database including only physicians but not nurses. However, it is unlikely that other trained staff or nurses could apply different TTM prescriptions as compared with those declared in the present survey. Third, it could be argued that our survey only concerns intensivists working in France. However, the FICS includes several responders from numerous French-speaking countries, herein reaching $13 \%$ of respondents of this survey. Because only French-speaking physicians were here able to respond, our results can mainly be applied for Frenchspeaking countries. Considering the high rate $(98 \%)$ of $\mathrm{TH}$ implementation in France as previously published [20], our result regarding the percentage of TH changes induced by the TTM publication seems likely. Finally, our survey collected answers from some responders working in the same ICU that could lead to bias. However, 264 ICUs from 11 countries were involved in the present survey, showing a large representative response to correctly evaluate the TTM and cooling changes.

\section{Conclusion}

The TTM trial publication showing no main difference between 36 and $33{ }^{\circ} \mathrm{C}$ after $\mathrm{CA}$ has induced a modification of current practices in one-third of respondents. However, the $32-34{ }^{\circ} \mathrm{C}$ target temperature remained unchanged for $56 \%$ of respondents. Prospective epidemiologic studies may evaluate the impact on patients' outcome of those practices. Educational actions are needed to promote better knowledge translations of trial results and guidelines into clinical practice.

\section{Additional files}

Additional file 1. French questionnaire.

Additional file 2. Additional Figures S1-S9 and Tables S1-S2.

\begin{abstract}
Abbreviations
CA: cardiac arrest; FICS/SRLF: French Intensive Care Society (société de réanimation de langue française); ICU: intensive care unit; ILCOR: international liaison committee on resuscitation; TH: therapeutic hypothermia; TTM: targeted
\end{abstract} temperature management; ROSC: return of spontaneous circulation.

\section{Authors' contributions}

All authors have made substantive intellectual contributions to the study: substantial contributions to conception and design, acquisition of data, analysis and interpretation of data, and/or drafting or revising the manuscript. Details are as follows: ND' participation: study concept and design, acquisition of data, analysis and interpretation of data, drafting of the manuscript, critical revision of the manuscript for important intellectual content, and general study supervision; FV'participation: study concept and design, acquisition of data, analysis and interpretation of data, drafting of the manuscript, and critical revision of the manuscript for important intellectual content; $P M^{\prime}$ participation: statistical analysis, and critical revision of the manuscript for important intellectual content; SE' participation: study concept and design, acquisition of data, analysis and interpretation of data, drafting of the manuscript, and critical revision of the manuscript for important intellectual content; DDS' participation: study concept and design, acquisition of data, analysis and interpretation of data, and critical revision of the manuscript for important intellectual content; MP' participation: study concept and design, acquisition of data, analysis and interpretation of data, drafting of the manuscript, and critical revision of the manuscript for important intellectual content; AK' participation: study concept and design, acquisition of data, analysis and interpretation of data, and critical revision of the manuscript for important intellectual content; $\mathrm{OH}^{\prime}$ participation: study concept and design, acquisition of data, analysis and interpretation of data, and critical revision of the manuscript for important intellectual content; JCL' participation: study concept and design, acquisition of data, analysis and interpretation of data, and critical revision of the manuscript for important intellectual content; BDJ' participation: study concept and design, acquisition of data, analysis and interpretation of data, and critical revision of the manuscript for important intellectual content; FB' participation: study concept and design, acquisition of data, analysis and interpretation of data, and critical revision of the manuscript for important intellectual content; CA' participation: study concept and design, acquisition of data, analysis and interpretation of data, and critical revision of the manuscript for important intellectual content; XM' participation: study concept and design and critical revision of the manuscript for important intellectual content; PFL' participation: study concept and design and critical revision of the manuscript for important intellectual content. All authors read and approved the final manuscript.

\section{Author details}

${ }^{1}$ Réanimation Médicale et Toxicologique, Unité Inserm U942, Centre Hospitalier Universitaire Lariboisière, Assistance Publique des Hôpitaux de Paris, 2, rue Ambroise Paré, 75010 Paris, France. ${ }^{2}$ Réanimation Polyvalente, Groupe Hospitalier Inter-Communal Le Raincy-Montfermeil, Montfermeil, France. ${ }^{3}$ Réanimation Polyvalente, Centre Hospitalier Régional René Dubost, Pontoise, France.

${ }^{4}$ Réanimation Polyvalente, Centre Hospitalier Régional Universitaire, Tours, France. ${ }^{5}$ Réanimation, Centre Hospitalier Delafontaine, Saint-Denis, France. ${ }^{6}$ Department of Intensive Care Experimental Medicine Laboratory, Centre Hospitalier Universitaire, Charleroi, Belgium. ${ }^{7}$ Réanimation Médicale, Centre Hospitalier Universitaire de Nancy Brabois, Vandoeuvre-les-Nancy, France.

${ }^{8}$ Réanimation Polyvalente, Hôpital Antoine Béclère, APHP, Clamart, France. ${ }^{9}$ Réanimation Polyvalente, Centre Hospitalier Départemental Les Oudairies, La Roche-Sur-Yon, France. ${ }^{10}$ Réanimation Médicale, Centre Hospitalier Inter-Communal, Poissy, France. ${ }^{11}$ Clinique des Cèdres-Cornebarrieu, Blagnac, France. ${ }^{12}$ Réanimation Médicale, Centre Hospitalier Universitaire Paris-Sud, APHP, Kremlin-Bicêtre, France. ${ }^{13}$ Medical-surgical intensive care unit, Saint Luc University Hospital, Université Catholique de Louvain, Brussels, Belgium.

\section{Acknowledgements}

We also thank Chantal Sevens, Mathieu Lloung, and Jean-Paul Gouello for their precious help regarding the administrative, technical, and material support for the web-survey finalization.

\section{Competing interests}

All authors declare that they have no financial and non-financial competing interests in relation with this paper. Additionally, none of the authors have received any financial compensation for this research. No specific research grant was obtained for performing this study.

Received: 15 July 2015 Accepted: 27 December 2015

Published online: 12 January 2016

\section{References}

1. Bernard SA, Gray TW, Buist MD, Jones BM, Silvester W, Gutteridge G, et al. Treatment of comatose survivors of out-of-hospital cardiac arrest with induced hypothermia. N Engl J Med. 2002;346:557-63.

2. HACA. Mild therapeutic hypothermia to improve the neurologic outcome after cardiac arrest. N Engl J Med. 2002;346:549-56.

3. Morrison LJ, Deakin CD, Morley PT, Callaway CW, Kerber RE, Kronick SL, et al. Part 8: advanced life support: 2010 international consensus on cardiopulmonary resuscitation and emergency cardiovascular care science with treatment recommendations. Circulation. 2010;122:S345-421.

4. Nunnally ME, Jaeschke R, Bellingan GJ, Lacroix J, Mourvillier B, RodriguezVega GM, et al. Targeted temperature management in critical care: a 
report and recommendations from five professional societies. Crit Care Med. 2011;39:1113-25.

5. Holzer M. Targeted temperature management for comatose survivors of cardiac arrest. N Engl J Med. 2010;363:1256-64.

6. Nielsen N, Wetterslev J, Cronberg T, Erlinge D, Gasche Y, Hassager C, et al. Targeted temperature management at 33 versus $36^{\circ} \mathrm{C}$ after cardiac arrest. N Engl J Med. 2013;369:2197-206.

7. Rittenberger JC, Callaway CW. Targeted temperature management after cardiac arrest. N Engl J Med. 2014;370:1360-1.

8. Kudenchuk PJ, Sandroni C, Drinhaus HR, Bottiger BW, Cariou A, Sunde K, et al. Breakthrough in cardiac arrest: reports from the 4th Paris International Conference. Ann Intensive Care. 2015;5:22.

9. Jacobs I, Nadkarni V. Targeted temperature management following cardiac arrest: An update. http://www.ilcororg/data/TTM-ILCOR-updateDec-2013pdf. 2013.

10. Vargas M, Servillo G, Sutherasan Y, Rodríguez-González R, Brunetti I, Pelosi P. Effects of in-hospital low targeted temperature after out of hospital cardiac arrest: a systematic review with meta-analysis of randomized clinical trials. Resuscitation. 2015;91:8-18.

11. Abella BS, Rhee JW, Huang KN, Vanden Hoek TL, Becker LB. Induced hypothermia is underused after resuscitation from cardiac arrest: a current practice survey. Resuscitation. 2005;64:181-6.

12. Merchant RM, Soar J, Skrifvars MB, Silfvast T, Edelson DP, Ahmad F, et al. Therapeutic hypothermia utilization among physicians after resuscitation from cardiac arrest. Crit Care Med. 2006;34:1935-40.

13. Wolfrum S, Radke PW, Pischon T, Willich SN, Schunkert H, Kurowski V. Mild therapeutic hypothermia after cardiac arrest — a nationwide survey on the implementation of the ILCOR guidelines in German intensive care units. Resuscitation. 2007;72:207-13.

14. Bianchin A, Pellizzato N, Martano L, Castioni CA. Therapeutic hypothermia in Italian intensive care units: a national survey. Minerva Anestesiol. 2009;75:357-62.

15. Laver SR, Padkin A, Atalla A, Nolan JP. Therapeutic hypothermia after cardiac arrest: a survey of practice in intensive care units in the United Kingdom. Anaesthesia. 2006:61:873-7.

16. Nolan JP, Morley PT, Hoek TL, Hickey RW. Therapeutic hypothermia after cardiac arrest. An advisory statement by the Advancement Life support Task Force of the International Liaison committee on Resuscitation. Resuscitation. 2003;57:231-5.

17. Krawczyk P, Fraczek B, Drab E. Use of therapeutic hypothermia in Polish intensive care units. Resuscitation. 2008;79:339.

18. Krawczyk P, Kolodziej G, Szpyra B, Andres J. Implementation of therapeutic hypothermia after cardiac arrest in intensive care units in Poland. Kardiol Pol. 2013;71:270-4.

19. Binks AC, Murphy RE, Prout RE, Bhayani S, Griffiths CA, Mitchell T, et al. Therapeutic hypothermia after cardiac arrest-implementation in UK intensive care units. Anaesthesia. 2010;65:260-5.

20. Orban JC, Cattet F, Lefrant JY, Leone M, Jaber S, Constantin JM, et al. The practice of therapeutic hypothermia after cardiac arrest in France: a national survey. PLoS One. 2012;7:e45284.

21. Rittenberger JC, Callaway CW. Temperature management and modern post-cardiac arrest care. N Engl J Med. 2013;369:2262-3.

22. Niven DJ, Rubenfeld GD, Kramer AA, Stelfox HT. Effect of published scientific evidence on glycemic control in adult intensive care units. JAMA Intern Med. 2015:175:801-9.

23. Donnino MW, Andersen LW, Berg KM, Reynolds JC, Nolan JP, Morley PT et al. Temperature management after cardiac arrest: an advisory statement by the Advanced Life Support Task Force of the International Liaison Committee on Resuscitation and the American Heart Association Emergency Cardiovascular Care Committee and the Council on Cardiopulmonary, Critical Care, Perioperative and Resuscitation. Circulation. 2015

24. Kim YM, Kim JH, Park KN. Use of therapeutic hypothermia after cardiac arrest: a survey of the society of critical care medicine in South Korea. Resuscitation. 2009:80:836.

25. Gasparetto N, Scarpa D, Rossi S, Persona P, Martano L, Bianchin A, et al. Therapeutic hypothermia in Italian Intensive Care Units after 2010 resuscitation guidelines: still a lot to do. Resuscitation. 2014;85:376-80.
26. Polderman $\mathrm{KH}$. How to stay cool in the ICU? Endovascular vs. surface cooling. Circulation. 2015

27. Deye N, Cariou A, Girardie P, Pichon N, Megarbane B, Midez P, et al. Endovascular versus external targeted temperature management for patients with out-of-hospital cardiac arrest: a randomized, controlled study. Circulation. 2015;132:182-93.

28. Kliegel A, Gamper G, Mayr H. Therapeutic hypothermia after cardiac arrest in Lower Austria-a cross-sectional survey. Eur J Emerg Med. 2011:18:105-7.

29. Wolfrum S, Pierau C, Radke PW, Schunkert H, Kurowski V. Mild therapeutic hypothermia in patients after out-of-hospital cardiac arrest due to acute ST-segment elevation myocardial infarction undergoing immediate percutaneous coronary intervention. Crit Care Med. 2008;36:1780-6.

30. Merchant RM, Abella BS, Peberdy MA, Soar J, Ong ME, Schmidt GA, et al. Therapeutic hypothermia after cardiac arrest: unintentional overcooling is common using ice packs and conventional cooling blankets. Crit Care Med. 2006;34:S490-4.

31. da Silva D, Aboab J, Blayau C, Tassin C, Josserand J, Gaudry S, et al. Cardiac arrest in France: so cool intensive care units. Intensive Care Med 2009;35:S210.

32. Bernard SA, Smith K, Cameron P, Masci K, Taylor DM, Cooper DJ, et al. Induction of therapeutic hypothermia by paramedics after resuscitation from out-of-hospital ventricular fibrillation cardiac arrest: a randomized controlled trial. Circulation. 2010;122:737-42.

33. Kim F, Nichol G, Maynard C, Hallstrom A, Kudenchuk PJ, Rea T, et al. Effect of prehospital induction of mild hypothermia on survival and neurological status among adults with cardiac arrest: a randomized clinical trial. JAMA. 2014;311:45-52.

34. Nolan JP, Soar J, Cariou A, Cronberg T, Moulaert VR, Deakin CD, et al. European Resuscitation Council and European Society of Intensive Care Medicine Guidelines for Post-resuscitation Care 2015: section 5 of the European Resuscitation Council Guidelines for Resuscitation 2015. Resuscitation. 2015;95:202-22

35. Bjelland TW, Dale O, Kaisen K, Haugen BO, Lydersen S, Strand K, et al. Propofol and remifentanil versus midazolam and fentanyl for sedation during therapeutic hypothermia after cardiac arrest: a randomised trial. Intensive Care Med. 2012;38:959-67.

36. Sandroni C, D'Arrigo S. Management of oxygen and carbon dioxide pressure after cardiac arrest. Minerva Anestesiol. 2014;80:1105-14.

37. Roberts BW, Karagiannis P, Coletta M, Kilgannon JH, Chansky ME, Trzeciak S. Effects of PaCO derangements on clinical outcomes after cerebral injury: a systematic review. Resuscitation. 2015;91:32-41.

38. Daviaud F, Dumas F, Demars N, Geri G, Bougle A, Morichau-Beauchant $\mathrm{T}$, et al. Blood glucose level and outcome after cardiac arrest: insights from a large registry in the hypothermia era. Intensive Care Med. 2014;40:855-62.

39. Duffett M, Burns KE, Adhikari NK, Arnold DM, Lauzier F, Kho ME, et al. Quality of reporting of surveys in critical care journals: a methodologic review. Crit Care Med. 2012:40:441-9.

40. Tinsley A, Naymagon S, Trindade AJ, Sachar DB, Sands BE, Ullman TA. A survey of current practice of venous thromboembolism prophylaxis in hospitalized inflammatory bowel disease patients in the United States. J Clin Gastroenterol. 2013:47:e1-6.

41. Sinclair M, O'Toole J, Malawaraarachchi M, Leder K. Comparison of response rates and cost-effectiveness for a community-based survey: postal, internet and telephone modes with generic or personalised recruitment approaches. BMC Med Res Methodol. 2012;12:132.

42. S.R.L.F. Sedation in French intensive care units: a survey of clinical practice. Ann Intensive Care. 2013;3:24

43. Bigham BL, Dainty KN, Scales DC, Morrison LJ, Brooks SC. Predictors of adopting therapeutic hypothermia for post-cardiac arrest patients among Canadian emergency and critical care physicians. Resuscitation. 2010;81:20-4.

44. Friberg $\mathrm{H}$, Cronberg T, Dunser MW, Duranteau J, Horn J, Oddo M. Survey on current practices for neurological prognostication after cardiac arrest. Resuscitation. 2015;90:158-62. 